\title{
PROBLEMS OF LEGAL REGULATION OF ARTIFICIAL INTELLIGENCE IN LABOR LAW OF DEVELOPED COUNTRIES
}

\author{
Oleg M. Yaroshenko ${ }^{1}$, Nataliia O. Melnychuk ${ }^{2}$ Ivan P. Zhygalkin ${ }^{3}$, Serhii O. \\ Silchenko ${ }^{4}$ Daria I. Zaika ${ }^{5}$ \\ Department of Labor Law, Yaroslav Mudryi National Law University, Kharkiv, Ukraine ${ }^{1}$; Departament of Labor Law and Social \\ Security Law, Institute of Law of Taras Shevchenko National University of Kyiv, Kyiv, Ukraine ${ }^{2}$; Department of Civil Law No. \\ 1, Yaroslav Mudryi National Law University, Kharkiv, Ukraine3; Department of Labor Law, Yaroslav Mudryi National Law \\ University, Kharkiv, Ukraine; ; Department of Labor Law, Yaroslav Mudryi National Law University, Kharkiv, Ukraine ${ }^{5}$
}

\section{Abstract}

The robotization process leads to the emergence of new subjects of legal regulation, which includes the search for new solutions in various areas of legal, economic and social development. The aim of the study. based on the analysis of international legal acts, the legislation of developed countries, as well as doctrinal provisions in the field of legal regulation of artificial intelligence, so it is necessary to characterize the directions, review the current state of research, list the main trends, and also make a comparative legal analysis of the development of legal regulation of artificial intelligence in labor law. It was made an analysis of the existing positions on a controversial issue among the authors. The authors have been made a classification of the approaches to the legal understanding of artificial intelligence, which were proposed in the scientific literature previously. The provisions of the legislation of developed countries in the field of legal regulation of artificial intelligence were compared, which made it possible to use positive experience to develop proposals for improving the norms of legislation. It is highlighted the need to create a convention at the international level that would be binding and standardize the legal regulation of artificial intelligence at the global level. It is argued that the responsibility for the actions or inactions of artificial intelligence is borne by the person who develops and programs the artificial intelligence.

Keywords: legal status of artificial intelligence, legal personality of artificial intelligence, responsibility of artificial intelligence, international legal acts, labor law.

\section{INTRODUCTION}

Today, it is possible to distinguish three major industrial revolutions of technological development, inter alia: the first is associated with the development of the railway and the steam engine for the mechanization of production; the second is related to electricity and the development of mass production; the third revolution is based on the emergence of computers, information technology, robotics and artificial intelligence for industrial automation. At the same time, the artificial intelligence revolution is different from the transformations that have taken place in the world of work in the past. The fundamental difference is in the speed of the changes taking place. The entire socio-economic system is entering a phase of accelerated transformation, which will have a major impact on the models of markets, business, education, governance, welfare and employment. New technologies are changing our daily lives and raising ethical questions that never existed before. The changes in the lives of people 
that bring artificial intelligence are difficult to compare with what appeared earlier. Humanity can lose most of the known professions /1/.

Currently, robots are regarded as technologies that can replace a person, perform his/her functions, including labor, independently, and also adapt to the conditions of the surrounding world. Thus, according to the forecast of the McKinsey World Institute, by 2030 about 400 million people (or $14 \%$ of the workforce) on the planet will lose their jobs due to the fact that their functions will be performed using digital technologies /2/. It should be noted, that artificial intelligence and algorithmic systems already guide a vast array of decisions in both private and public sectors. Artificial intelligence is widely used in education, healthcare, pensions, environmental protection, government, and law enforcement. For example, private global platforms, such as Google and Facebook, use artificial intelligence-based filtering algorithms to control access to information /3/.

In the field of transportation, artificial intelligence is able to ensure the safety of vehicles and strict adherence to timetables. In jurisprudence, it is observed the development of the e-justice system. In medicine, artificial intelligence technologies can be used for diagnostic procedures and their analysis, as well as for continuous monitoring of the condition of patients, communication with them. In the field of security, national defense, crime prevention, astrophysics and astronautics, etc. robots equipped with artificial intelligence are capable of performing work that can be dangerous for humans. Governments can use artificial intelligence-technologies to improve the quality of public services, to foster citizens' trust, and to increase efficiency and effectiveness in service delivery $/ 4 /$. That is why the leadership of all developed countries is interested in a large-scale buildup of technologies for the development and use of artificial intelligence, since the position of the country in the international arena in terms of economy, security, etc. directly depends on this.

In turn, the development of artificial intelligence and robotics leads to the need for their clear legal regulation. Foreign countries, in particular Japan, the USA, South Korea, China, the countries of the European Union, are actively introducing artificial intelligence into their legislation. Moreover, some researches claim that robots will become so important to mankind that a new branch of the law is needed, to grant their race and its individual members the benefits of legal protection, much like the international community did, or tried to, with the environment $/ 5 /$. Although it should be noted that today, there are a number of gaps in the international legal and national regulation of this issue. Inter alia, such issues are needed to be addressed: regulation of the legal personality of artificial intelligence products; legal consequences of lawful or illegal actions of artificial intelligence, and so on. Thus, the impact of technology on the law that regulates relations in the world of work is of scientific interest and seems to be a promising topic for the development of a research nature, which has both scientific value and practical significance.

\section{LITERATURE REVIEW}

In science, there are a lot of different approaches to the interpretation of the concept of artificial intelligence. At the same time, today there is no single approach for understanding artificial intelligence in the technical sphere, and this creates uncertainty in the legal, social and moral-ethical spheres as well. For the first time the concept of artificial intelligence was introduced into scientific circulation by one of the leading cybernetics J. McCarthy from Stanford University in the second half of the 50s. last century /6/. He defined artificial intelligence, on the one hand, as the science and technology of creating intelligent machines, and on the other, as the ability of a computer to do what people can do, i.e. what is associated with intelligence. R. Engelmore notes that some researchers refer to symbolic computation as artificial intelligence, while others refer to expert systems as artificial intelligence. There is an explanation of the concept of artificial intelligence through the concept of "cutting edge problems in computer science" /7/. The issues of professional development of employees are becoming especially relevant in the context of globalization, as 
well as the European and innovative integration of Ukraine. The author investigates the peculiarities of transformations of modern theoretical and legal approaches to professional development of employees in the context of European integration, human-centered and innovative approaches to doing business $/ 8 /$.

R. Bellman /9/ interprets artificial intelligence through the concept of automating actions that we associate with human thinking, that is, actions such as decision making, problem solving, and learning. The first international conference on the legal regulation of artificial intelligence was held in 1987. In 1991 International Association for Artificial Intelligence was established /10/. At the same time, the issues of legal regulation of artificial intelligence and robots analized some researches. For example, N. Petit describes the four core elements of today's digital power concentration, which need to be seen in cumulation and which, seen together, are both a threat to democracy and to functioning markets /11/.S. Gerke /12/ studied the ethical and legal challenges of artificial intelligence-driven healthcare.

This group of authors believes, that preserving commercial secrets, maintaining the legal regime of their protection by all employees is important for ensuring economic security of an enterprise. Failure to comply with these rules even by a part of staff may significantly worsen the outcome of an economic activity; negate aspirations of other employees to economic growth of a company /13/. A. Atabekov A. and Yastrebov O. /14/ explore current legal regulation on Artificial Intelligence across countries. Their research argues that special emphasis should be laid to the prospective of treating artificial intelligence as an autonomous legal personality, separate subject of law and control. The article identifies major approaches in legislation and practice on state regulation of AI and explores a number of current options: AI as a subject of law introduced into national legislation without prior background, $\mathrm{AI}$ as a subject of law equal to a person, and regulated or not regulated by separate rules of law, etc.
The research evaluates current legal protection in Europe against discriminatory algorithmic decisions. The paper shows that non-discrimination law, in particular through the concept of indirect discrimination, prohibits many types of algorithmic discrimination /15/. A unique analysis of case law is presented in the work of R. Calo "Robots in American Law". The article analyzes court decisions that relate to robots. It is noteworthy that in terms of decisions, the courts try to analyze the problem of the legal personality of robots and compare humans and artificial intelligence. The author shows that robots have become a part of modern society and lawyers will inevitably have to solve complex legal and ethical issues in understanding and using smart machines /16/. If we talk about comparative analysis in several countries, we can turn to work where current issues of codification and improvement of labour legislation in Belarus and Ukraine was represented /17/.

O.V. Petryshyn and O.S. Hyliaka /18/ mentioned that current task should be to understand the existing ideas about digital rights and who they belong to and what they represent, what benefits they are intended to protect, how they correlate with fundamental rights and freedoms (how independent they are). Razmetaeva Yulia and Razmetaevthe Sergiy /19/ think that changes taking place in the digital era cannot but affect the justice sector, including the emergence and deployment of technological solutions, both replacement and complementary, with varying degrees of legal support and social thoughtfulness. But some authors believe that the most important problem of demographic policy and a necessary condition for ensuring the national security of Ukraine is increase of the reproductive potential and health preserving of the generation that is born $/ \mathbf{2 0}$.

\section{MATERIALS AND METHODS}

To achieve the aim of the article and ensure the scientific objectivity of the research results, a set of modern general scientific and special methods was chosen, which are used in legal science. All 
methods were applied in conjunction, which ultimately contributed to ensuring the comprehensiveness, completeness and objectivity of the results of scientific research, correctness and consistency of conclusions. Within the framework of general scientific methods, an analysis was made of the existing positions on a controversial issue among the authors. The description and comparison of legal positions on the legal regulation of the results of artificial intelligence in developed countries is carried out. A classification of the approaches to the legal understanding of artificial intelligence proposed in the scientific literature has been made.

The dialectical method of scientific knowledge became the methodological basis of the study, with its help, reasonable conclusions and recommendations were obtained in the field of legal regulation of artificial intelligence in the labor law of developed countries. This method contributed to an objective assessment of the existing legislation regarding the regulation of artificial intelligence. The article also used the methods of induction and deduction. In particular, with the help of the method of induction, knowledge of the general was made through the study of the individual and the particular, a prerequisite for which was acquaintance with the facts that reflect the corresponding properties of objects and phenomena. On the basis of their understanding, general characteristics of the problems of legal regulation of artificial intelligence in the labor law of developed countries were obtained.

Thus, with the help of induction, on the basis of knowledge about the individual, conclusions about the general were made, and with its help, assumptions and hypotheses were reasonably advanced. With the help of deductive inference, conclusions were drawn from one or more other statements, the truth of which has already been established. The generalization method provided an opportunity, based on a separate analysis of the practice of regulating artificial intelligence, to formulate scientifically based conclusions and make recommendations. Using the historical method, a study of the genesis of the legal regulation of artificial intelligence in the labor law of developed countries has been carried out. The formal-logical method was used to define the concept of artificial intelligence and clarify its essence.

Using the comparative method, the provisions of the legislation of developed countries in the field of legal regulation of artificial intelligence were compared, which made it possible, in particular, in the future to use positive experience to develop proposals for improving the norms of legislation. On the basis of the formal legal method, an analysis of legal terms, constructions and processes that are enshrined in the legislation on artificial intelligence was carried out. The normative and legal basis of the study were the provisions of: international legal acts regulating the issues of artificial intelligence, as well as the current legislation of developed countries in this area.

\section{RESULTS}

At the international level, in a number of international organizations, the problem of legal regulation of artificial intelligence is regulated. Such organizations include the Organization for Economic Cooperation and Development, the International Labor Organization, the European Union and others. For example, the Organization for Economic Cooperation and Development has adopted recommendations on strategies for information lawmaking on information communication technologies, etc. At the same time, the Organization for Economic Cooperation and Development defines artificial intelligence as a machine system, which can make forecasts, recommendations or decisions, injected on a real or virtual middle ground based on a given set of human goals. Moreover, such systems can be broken up for robots with a growing level of autonomy /21/.

A researchers' group of International Labor Organization in the report "The Economics of Artificial Intelligence: Implications for Future Work" noted that the ongoing wave of technological change based on advances in artificial intelligence has created risks of job losses and further rising inequality. According to the International Labor 
Organization, it is already necessary to address the issue of taxation of the use of robots that will replace human labor, introduce an unconditional basic income, and also try to "slow down" the processes, reducing the speed of introduction of new technologies in order to give more time to workers to adapt to new conditions /22/.

At the stage of creation of the European Economic Community, the main goals of future integration were defined, among which - the promotion of free movement of goods, persons, services and capital; development of a common commercial policy and development of competition law. The tasks set and further identified the main areas that are the subject of exclusive competence of the EU /23/. In the EU Recommendation of the Council on Artificial Intelligence from 2019 artificial intelligence is described as a highly developed system that analyzes the established conditions and makes to some extent autonomous decisions to achieve certain goals /24/. The European Parliament adopted Resolution 2015/2103 "Civil Law Regulations on Robotics" /25/ which is based on the 2014 report "Regulating Robotics: A Challenge to Europe", which became part of a large study "Perspectives on European Law" /26/. It should be noted, that the Resolution 2015/2103 "Civil Law Regulations on Robotics" /27/ clearly defines the principles and measures for the use of robots in various fields, as well as the boundaries of decision-making and responsibility.

At the same time, the EU notes that there is no universally recognized term for artificial intelligence either at the legal or at the technical level. In particular, the creators of the Resolution 2015/2103 "Civil Law Regulations on Robotics" believe that it is impossible to give an exact definition of artificial intelligence, due to the real existence of various types of robots. In this regard, in their opinion, the latter study should be approached casuistically, considering each robotic system separately. It should be noted that European Parliament Resolutions are, of course, not legally binding and do not enshrine any rights or obligations. However, the resolutions approved by the European Parliament highlight those areas that need to be regulated at the EU level. In the future, the European Parliament proposes to consider the issue of endowing robots with an independent legal status for those cases when robots, as electronic persons, make decisions autonomously.

It should be mentioned, that among the positive aspects of the resolution of the European Parliament could be distinguished the following: an integrated approach to the regulation of robotics, taking into account the achievements of technical science, ethics and law; the recommendation of the European Commission to create an EU Agency for Robotics and Artificial Intelligence, which would act as a regulator of the legal, technical and ethical aspects of the use of smart robots; objectivity and caution, taking into account both the benefits and threats posed by the use of artificial intelligence. A separate subject of research is ethical issues in the use of artificial intelligence, which are reflected in the Charter of Robotics - an appendix to the resolution of the European Parliament. It is absolutely true that the European Parliament has come to a conclusion regarding the development of not only legal, but also ethical standards in the field of artificial intelligence. Robotics irrevocably raises a number of philosophical and ethical questions: recognition of smart robots as a person similar to a human; the admissibility of using robots in a number of spheres of life; the possibility of using robots as weapons; respect for privacy and family life in case of contact with robots.

The Charter of Robotics formulates ethical principles for researchers of robotics: 1) the principle of "do good", which determines the use of robots in the interests of people; 2) the principle of "do no harm", aimed at preventing harm to people when using robots; 3) the principle of independence, which means a person's right to independently decide the issue of the possibility of interaction with a robot; 4) the principle of fairness, according to which all benefits obtained from the use of robots should be distributed fairly. The Robotics Charter emphasizes the principles of the robotics research ethics committee, as well as ethical 
standards for developers and users of smart robots. First of all, the Charter emphasizes the need to respect human dignity and privacy when interacting with a robot and prohibits the use of a robot as a means of causing harm (weapon). Moreover, it is the developers who are responsible for all possible harmful consequences. It should be noted, that the development of certain European legal standards for robotics and artificial intelligence will promote the development of the relevant industry and ensure respect for human rights in the formation of new social relations with the participation of autonomous devices.

Thus, the rapid growth in the use of artificial intelligence technologies in various spheres of the economy contributes to the development of the activities of subjects of international law to form an international legal framework on this issue. International organizations are increasingly raising issues related to the discussion of draft international treaties related to the regulation of artificial intelligence. At the same time, international legal acts are mainly advisory in nature. Despite the spread of new technologies in the world as a whole, the issues arising in connection with these processes are currently being resolved by referring to already existing international treaties, as well as to general legal principles. At the national level, for the first time, South Korean scientists spoke about the need for legal regulation of the relationship between humans and artificial intelligence, and South Korean lawmakers became pioneers in the normative consolidation of such provisions as: "Korean Law for the Development of Artificial Intelligence of Robots" from 2005, "Ethical Charter of Robots" from 2007 and "Legal Regulation of Autonomous Systems in South Korea" from 2012/28/.

They stated the need for detailed regulation of the activities of the creators of programs for the functioning of robots, as well as those involved in their development and production, use and destruction. In addition, South Korea's 2008 Law "On Promoting the Development and Distribution of Smart Robots" from 2008 proposes the following definition of a smart robot: a mechanical device that is capable of perceiving its environment, recognizing the circumstances in which it operates, and purposefully moving around on its own. In the United States, the Roadmap for US Robotics (2011, 2016, 2019) and the National Robotics Initiative (2011，2016，2019) are being implemented $/ 29 /$. Also, in the United States, the first precedent for the protection of the rights of robots can be determined - the creation in 1999 in the United States of the American Society for the Prevention of Violence against Robots, whose mission is to guarantee the right to exist, independence and the desire for knowledge of all artificially created intelligent beings, commonly known as "robots".

Japan has developed and implemented the Guiding Principles aimed at ensuring the safety of the use of robots of a new generation, "Japan Plan for Economic Revitalization”, "New Robot Strategy. Japanese robot strategy: overview, strategy, action plan". Thus, the New Strategy of Robots formulates conceptual approaches to the implementation of robotics for the next 5 years. In particular, the Strategy stipulates that works can be used in all spheres of everyday life, including, for example, to help the elderly, to ensure the safety and comfort of society $/ 30 /$. China has adopted the Guidelines on Promoting the Development of Industrial Robots from 2014 and the global government development program "Made in China 2025 " /31/. At the same time, a collection of ethics for robotic vehicles was approved in Germany in June 2017 /32/.

\section{DISCUSSION}

Artificial intelligence is central to the massive digital transformation of the current industrial revolution and has the potential to have a significant impact on many areas of life $/ 33 /$. At the same time, artificial intelligence is becoming good at many "human" jobs - diagnosing disease, translating languages, providing customer service and it is improving fast. This is raising reasonable fears that artificial intelligence will ultimately replace human workers throughout the economy 
/34/. There are high expectations that artificial intelligence will change our existence as humans in all aspects of our lives. But for employers, artificial intelligence will have a profound impact on how they conduct their business. Artificial intelligence will ultimately affect the employment law across all states. That is why it is necessary to introduce legal regulation of relations in the field of robotics in connection with the creation, commissioning, use of robots, as well as the independent operation of autonomous robots.

Artificial intelligence will affect labor relations in three main areas: building human-machine interaction (including through the development of chat bots, communication in language without the need to learn programming in artificial language); intelligent automation of processes (replacing people with robots); analytical work and machine learning: analyzing large amounts of information and choosing the optimal solution, for example, artificial intelligence systems, are already able to successfully solve the problem of predicting the outcome of a case than qualified lawyers ( $86 \%$ versus $62.3 \%$ ) $/ 35 /$.

At the same time, it should be noted that in the coming years there will not be a complete replacement of humans with robots, but the flow of jobs from old sectors of the economy to new ones will increase with the establishment of the coexistence of artificial and natural intelligences together. The appearance of robots in neighboring workplaces with people entails the emergence of new risks and creates working conditions that are not provided for by the current labor legislation. It is necessary to foresee what legal problems arise with the emergence of fellow robots. Legislation regulating working conditions has emerged in an industrial society; a set of new risks and situational issues related to the development of technologies are not taken into account. Such legislation is not able to effectively protect workers when introducing artificial intelligence systems into production and professional services.

One of the issues is the recognition of the legal personality of artificial intelligence. Interestingly, in October 2017, the human-like robot Sofia received the status of a citizen of Saudi Arabia, although it did not become the first robot to receive full legal personality. This fact caused many legal conflicts and showed the inadequacy of domestic law to such radical changes. To some extent, this is due to the fact that citizenship, as a certain legal relationship between an individual and the state, is narrower in content than legal personality. Legal personality covers much more than legal capacity, namely, the issues of legal capacity and tort, which are in no way regulated in relation to robots in Saudi Arabia. Therefore, the issue of recognizing the legal personality of robots was premature in Saudi law. It can be assumed that in the coming years, artificial intelligence will not be able to finally equalize human rights and act as an independent subject of legal relations $/ 36 /$.

Giving artificial intelligence legal personality can still help to decide who is responsible for its wrongdoing or inaction, in particular to solve the problem of determining the right defendant. Today, there is a need for legal regulation in the field of labor safety, when robots share the workspace with people. Safety standards must be developed and approved, including at the international level. The most important problem is the issue of distribution of responsibility. Who will be responsible for violation of the law by the robot worker: the employer, the human worker - the direct supervisor of the robot worker, the robot itself or its manufacturer /37/. In this aspect, the position of P. Cerke seems to be interesting, who sees two options for solving the issue of liability for harm caused in connection with the use of artificial intelligence: 1) the imposition of responsibility on the person who programs the artificial intelligence using, by analogy with Art. 12 of the UN Convention on the Use of Electronic Technologies in International Contracts; 2) the use of the theory of "big pocket" ("deeppocket") through the institution of insurance or wealthy and interested corporations /38/.

On the other hand, the proposal of some scientists to endow artificial intelligence with special legal capacity, as well as the recommendation to 
endow the most advanced robots with the status of an "electronic person" capable of taking responsibility for harm caused by them in cases where they make decisions on their own, without human intervention, can be applicable only to the civil law sphere. In cases with administrative and criminal liability, such an approach is not acceptable, since for their implementation it is necessary to consciously exercise rights and fulfill obligations. These types of responsibility are inextricably linked with the psychology of a person's personality, with the feeling and awareness of such responsibility /39/. In our study, we believe that the responsibility for the actions or inactions of artificial intelligence lies with the person who develops and programs the artificial intelligence /40/. All of the above allows us to conclude that the adaptation of labor law to the new reality is inevitable. Legislative changes of this scale should take into account many factors, including the need to increase the flexibility of legal regulation while maintaining the social orientation of labor law, the timeliness of legal response measures, taking into account the growing level of robotization of production and the steadily continuing intellectual automation of processes /41/.

\section{CONCLUSION}

Legal regulation of new or evolving phenomena always presents significant difficulties for the legislator, regardless of the branch of law. Today, it is necessary to ensure proper legal regulation of such rapidly developing areas of technology as artificial intelligence. Most of all, it is necessary to determine how to solve problems that may arise in connection with the use of artificial intelligence long before the moment when these problems arise in real life. That is why, it should be noted, that the use of artificial intelligence at the current stage of development of legislation is not fully regulated. For example, if in the developed countries laws and judicial practices are already appearing, in the countries that are developing this issue is more at the level of doctrine.

It should be also noted that standardization in this area should be carried out at the global level.
Taking into account the fact that the adopted international legal acts in the field of regulation of artificial intelligence have the nature of soft law, it is necessary to develop and adopt at the international level a convention that would have a legally binding nature. Also in this regard, it is necessary to propose directions for the development of the artificial intelligence in both national and international law; to investigate legally significant problems arising in connection with new developments of artificial intelligence, as well as those associated with the use of already existing types of autonomous intelligent systems, including transport, communication, security, etc.

It is also necessary to formulate approaches to a future strategy or concept of legal regulation of artificial intelligence both at the international level and at the national level. In addition, it is necessary to formulate the legal status of artificial intelligence, responsibility for its labor activity; to determine the framework of the legal personality of artificial intelligence. It could be also relevant to establish the admissibility and limits of application of modern rules of law on liability (administrative, civil, criminal) in relation to developers of artificial intelligence systems, their operators and others.

\section{Notes}

/1/ Onyshchuk, I.I. (2020), Legal regulation of artificial intelligence technologies: theoretical, practical and ethical basis. Scientific Papers of the Legislation Institute of the Verkhovna Rada of Ukraine, 3, 50-57.

/2/ Frey, C.B., \& Osborne, M.A. (2013), The future of employment: how susceptible are jobs to computerisation? Oxford: University of Oxford. Retrieved from https://www.oxfordmartin.ox.ac.uk/downloads/academic/future-of-employment.pdf

/3/ Gasser, U., \& Virgilio, A.F., (2017), A layered model for ai governance. IEEE Internet Computing, 6, 5862.

/4/ Zuiderwijka, A., Chenb, Yu., \& Salemc, F. (2021), Implications of the use of artificial intelligence in public governance: A systematic literature review and a research agenda. Government Information Quarterly, 3, 1-19.

15/ Petit, N. (2017), Law and regulation of artificial intelligence and robots - conceptual framework and 
normative implications. Retrieved from https://ssrn.com/abstract=2931339

/6/ McCarthy, J., Minsky, M.L., Rochester, N., \& Shannon, C.E. (2006), A proposal for the Dartmouth summer research project on artificial intelligence. AI Magazine, 4, 12-14.

/7/ Engelmore, R.S. (1987), Artificial intelligence and knowledge based systems: origins, methods and opportunities for NDE. Knowledge Systems Laboratory. Computer Science Department. Stanford University, 6, 1-20.

18/ Yaroshenko, O. M., Vapnyarchuk, N. M., Burnyagina, Y. M., Kozachok-Trush, N. V., \& Mohilevskyi, L. V. (2020), Professional development of employees as the way to innovative country integration. Journal of Advanced Research in Law and Economics, 11(2), 683-695.

/9/ Bellman, R.E. (1978), An introduction to artificial intelligence: can computers think? San Francisco: Boyd \& Fraser Publishing Company; Thomson Course Technology.

/10/ Yara, O., Brazheyev, A., Golovko, L., \& Bashkatova, V. (2021), Legal regulation of the use of artificial intelligence: problems and development prospects. European Journal of Sustainable Development, 10(1), 281-289.

/11/ op. sit. in /5/

/12/ Gerke, S., Minssen, T., \& Cohen, G. (2020), Ethical and legal challenges of artificial intelligence-driven healthcare. Artificial Intelligence in Healthcare, 1, 295336.

/13/ Yaroshenko, O. M., Moskalenko, O. V., Sliusar, A. M., \& Vapnyarchuk, N. M. (2018), Commercial secret as an object of labour relations: Foreign and international experience. Journal of Legal, Ethical and Regulatory Issues, 21(1), 1-10. Retrieved from https://www.abacademies.org/articles/Commercial-secret-as-an-object-of-labour-relations-foreignand-international-experience-1544-0044-21-S1253.pdf

/14/ Atabekov, A., \& Yastrebov, O. (2018), Legal status of artificial intelligence across countries: legislation on the move. European Research Studies Journal, 4, 773-782.

/15/ Frederik, J., \& Zuiderveen B. (2020), Strengthening legal protection against discrimination by algorithms and artificial intelligence. The International Journal of Human Rights, 10, 1572-1593.

/16/ Calo, R. (2016), Robots in American law. University of Washington School of Law Research Paper, 4, 43-44 Retrieved from https://ssrn.com/abstract=2737598

/17/ Tomashevski, K., \& Yaroshenko, O. (2020), Problems of labour legislation codification in Belarus and Ukraine: History, current situation and prospects. Transition Studies Review, 27(2), 41-49.

/18/ Petryshyn, O.V., \& Hyliaka, O.S. (2021), Human rights in the digital age: Challenges, threats and prospects. Journal of the National Academy of Legal Sciences of Ukraine, 28(1), 15-23.

/19/ Razmetaeva, Yu. \& Razmetaev, S. (2021), Justice in the Digital Age: technological solutions, hidden threats and enticing opportunities. Justice in Eastern Europe, 2(10), 104-117.

/20/ Yavor, O. A., Nadon, V.V., \& Ruban, O.O. (2019), Transformation of legal regulation of family relations under the impact of scientific progress. Astra Salvensis, 1, 523-537.

/21/ Council on Artificial Intelligence. (2019), Recommendation of the Council on Artificial Intelligence. Retrieved from https://legalinstruments.oecd.org/en/instruments/oecd-legal-0449

/22/ Wisskirchen, G., Biacabe, B., Bormann U., Muntz, An., Niehaus, G., Jiménez, G., \& Brauchitsch S. B. (2017), Artificial intelligence and robotics and their impact on the workplace. London: IBA Global Employment Institute.

/23/ Pozova, D., (2017), Prospects of legal regulation of artificial intelligence under EU legislation. Journal of Civilian Studies, 27, 116-120.

/24/ op. sit. in /21/

/25/ Civil Law Rules on Robotics. (2015), European Parliament resolution with recommendations to the Commission on Civil Law Rules on Robotics. Retrieved from https://eur-lex.europa.eu/legal-content/EN/TXT/?uri=CELEX\%3A52017IP0051

/26/ European Commission. (2014), Communication from the Commission to the European Parliament and the Council. A new EU Framework to strengthen the Rule of Law. Retrieved from https://eur-lex.europa.eu/legal-content/EN/TXT/PDF/?uri=CELEX:52014DC0158\&fro $\mathrm{m}=\mathrm{NL}$

/27/ op. sit. in /25/

/28/ Korean law information center. (2021), Korean law information center. Retrieved from https://www.law.go.kr/LSW/eng/engLsSc.do?men uId $=2$

/29/ National Science Foundation. (2019), National robotics initiative 2.0: ubiquitous collaborative robots. Retrieved from https://www.nsf.gov/pubs/2019/nsf19536/nsf195 36.htm

/30/ Japan's Economic Revitalization. (2015), New robot strategy, Japan's robot strategy. Tokyo: Japan's Economic Revitalization. Retrieved from 
http://www.meti.go.jp/eng-

lish/press/2015/pdf/0123_01b.pdf

/31/ Ray, J., Atha, K, Francis, E, Dependahl, C., Mulvenon, J., Alderman, D., \& Ragland-Luce L.A. (2016), China's industrial and military robotics development. research report prepared on behalf of the U.S.China economic and security review commission. Washington: Center for Intelligence Research and Analysis. Retrieved from https://www.uscc.gov/sites/default/files/Research/DGI_China's\%20Industrial\%20and\%20Mi litary\%20Robotics\%20Development.pdf

/32/ Federal Ministry of Transport and Digital Infrastructure. (2017), Report of the Ethics Commission of the German Federal Ministry of Transport and Digital Infrastructure "Automated and connected control". Berlin: Federal Ministry of Transport and Digital Infrastructure. Retrieved from https://www.bmvi.de/SharedDocs/EN/publicatio ns/report-ethics-commission.pdf?_blob=publicationFile

/33/ Kemp, R. (2016), Legal aspects of artificial intelligence. London: Kemp IT Law. Retrieved from file://C:/Users/\%D0\%9F\%D0\%9A8/Downloads/Legal-Aspects-of-AI-Kemp-IT-Law-v1.0Nov-2016-2.pdf

/34/ Wilson, J., \& Daugherty, P. (2018), Collaborative intelligence: humans and AI are joining forces. Harvard Business Review. Retrieved from https://hbr.org/2018/07/collaborative-intelligence-humans-and-ai-are-joining-forces
/35/ Cross, M. (2017), Robot beats human lawyers in outcomes challenge. Retrieved from https://www.lawgazette.co.uk/practice/robotbeats-human-lawyers-in-outcomes-challenge/5063471.article

/36/ Martsenko, N. (2020), Determining the place of artificial intelligence in civil law. Studia Prawnoustrojowe, 47, 157-173.

/37/ Sayarer, J. (2017), You're hired - taking on robots as employees. Retrieved from http://www.faa.unisg.ch/files/cto_layout/downloads/presse/LexisNexis_You\%27re\%20hired\%20-\%20taking\%20on\%20robots\%20as\%20employees.pdf

/38/ Cerka, P., Grigiene, J., \& Sirbikyte, G. (2015), Liability for damages caused by artificial intelligence. Computer Law E Security Review, 31, 376389.

/39/ Mosechkin, I. (2019), Artificial intelligence and criminal liability: problems of formation of a new type of crime subject. Bulletin of St. Petersburg State University. Pravo, 10, 461- 476.

/40/ Petrov, R., \& Serdyuk, O. (2008), Ukraine: The quest for democratization between Europe and Russia. International Actors, Democratization and the Rule of Law: Anchoring Democracy? (pp. 189223). London: Routledge. DOI: 10.4324/9780203894699

/41/ Reznik, O., Getmanets, O., Kovalchuk, A., Nastyuk, V., \& Andriichenko, N. (2020), Financial security of the state. Journal of Security and Sustainability Issues, 9(3), 843-852 